\title{
Childhood caries and hospital admissions in England: a reflection on preventive strategies
}

\author{
Ronnie S. Levine ${ }^{1}$
}

\section{Key points}

In England, dental extractions under general anaesthesia can only be performed in hospital settings, often resulting in long delays for

children experiencing pain.
Dental extractions are by far the most common reason for children to be referred to hospital and the highest proportion of referrals are mostly in relatively small areas in northern England.
Since national and local preventative programmes have failed to reduce the prevalence of childhood caries and the need for hospital referral for extractions, there is an overriding case for targeted water fluoridation schemes.

\begin{abstract}
Dental caries is a largely preventable disease, yet the extraction of carious teeth is the most common reason for the hospital admission of children in England. This raises concern over the perceived failure of current preventive strategies. Despite a number of national and local preventive strategies, childhood caries remains most prevalent among the lower socioeconomic groups and ethnic minorities, especially in northern England. Often overlooked is the social and emotional impact of caries and dental treatment on the children and their families. More long-lasting can be the emotional, psychological and developmental impact on children of dental treatment and extractions under general anaesthesia, especially in unfamiliar hospital settings. Yet, the number of hospital admissions for the 5-9-yearold age group continues to rise and was 26,000 in England in 2018. The aim of this paper is to review the demographic and socioeconomic factors related to hospital admission of children for dental extractions, focusing on the localities with the highest proportions of hospital admissions. It is suggested that a reappraisal of the caries-preventive strategy in those areas of England with the highest proportion of hospital admissions is now urgently needed and the case is forcefully made for targeted water fluoridation.
\end{abstract}

\section{Introduction}

In April 2011, the Editor-in-Chief of the British Dental Journal (BDJ) used a biblical quotation 'Suffer little children' for the title of his editorial referring to the dramatic increase in the number of children admitted to hospital in England for the extraction of carious teeth and bemoaned the lack of progress in reducing childhood caries. ${ }^{1}$ This editorial followed from growing concerns over such hospital admissions and exploratory studies in the pages of the $B D{ }^{2,3,4,5,6,7}$ and elsewhere. ${ }^{8}$ In the past decade, the prevalence of childhood caries has fallen in many parts of the UK, especially in the southern regions of England and with notable success in Scotland,

'Department of Oral Surgery, University of Leeds School of Dentistry, Worsley Building, Clarendon Way, Leeds LS2 9LU, UK.

Correspondence to: Ronnie S. Levine

Email address: r.s.levine@leeds.ac.uk

Refereed Paper.

Accepted 31 August 2020

https://doi.org/10.1038/s41415-021-2945-8 which has an item-of-service remuneration scheme and benefits from greater per capita National Health Service (NHS) dental funding. Nevertheless, in many towns and cities in England, especially in northern regions, this has not happened, and both the prevalence of childhood caries and hospital admissions for dental extractions under general anaesthesia (DGA) remain stubbornly high, suggesting a failure of preventive primary care. ${ }^{9}$ However, it must be recognised that access to NHS dental services is subject to local contract and commissioning arrangements and investment in new hospital facilities.

The long-lasting emotional, psychological and developmental impact on the developing child of a DGA in an unfamiliar setting cannot be underestimated. ${ }^{10}$ In some hospitals, a combination of local anaesthesia administered under general anaesthesia (GA) is used to help reduce distress caused by post-operative pain and bleeding. Further distress can be caused by the delay between referral and admission. A study from North West England found that the average time from referral to admission was 137 days. ${ }^{11}$ The average age of the children was 6.78 years and they had on average five teeth extracted, ranging from one tooth to the removal of all teeth. The distress caused to the children and parents involved of prolonged pain, sleepless nights and missed schooling, and the additional and largely preventable burden on NHS resources exacerbated by the COVID-19 pandemic, must now be resolutely addressed.

The origin of the present requirement for young children in the UK to be referred to hospital for dental extractions, previously performed in primary care settings, can be traced to the late 1980s. Because of growing concerns over the standards of GA and response to related medical emergencies in UK dental practices, an expert working party was formed under the chairmanship of Professor David Poswillo. The report, published in 1990, made wide-ranging recommendations covering skills, drugs, equipment, training and dental practice requirements necessary to minimise the risks associated with GA for dental treatment. ${ }^{12}$ The required emergency 
drug list was extensive, and many primary care dentists felt that they lacked the training and competence to use them in an emergency situation, save for basic life support measures. Nevertheless, the report and the changes that followed probably saved many lives, with fatalities falling by half from six per million in the decades ending 1980 and 1990 to three per million in the following decade and zero in the present decade. $^{13}$

In November 1998, the General Dental Council issued revised guidance on the provision of GA for dental treatment. ${ }^{14}$ The guidance required that a DGA must be given or supervised by a medically qualified person. Following this guidance, the number of DGAs in the NHS General Dental Services in England decreased by almost $80 \%$. It is probable that most patients requiring treatment under GA were referred to the NHS community dental service clinics or NHS hospitals. A further consequence of the guidance was that it brought the standards for the provision of DGAs under the control of the Royal College of Anaesthetists.

The final stage in the ending of GA in UK dental practices came with the publication of a report commissioned by the UK Department of Health in July $2000 .{ }^{15}$ Its most far-reaching recommendation was that DGAs should only take place in a hospital setting no later than 31 December 2001. From that date, the provision
Table 1 Prevalence of experience of dental decay in five-year-olds in England by region $(2008,2012,2015,2017$ and 2019), reproduced with permission from Public Health England under the terms of the Open Government Licence ${ }^{19}$

\begin{tabular}{l|l|l|l|l|l}
\multirow{2}{*}{ Region name } & \multicolumn{5}{|l}{ Prevalence of experience of dental decay in five-year-olds (\%) } \\
\cline { 2 - 7 } & $\mathbf{2 0 0 8}$ & $\mathbf{2 0 1 2}$ & $\mathbf{2 0 1 5}$ & $\mathbf{2 0 1 7}$ & $\mathbf{2 0 1 9}$ \\
\hline North East & 39.8 & 29.7 & 28.0 & 23.9 & 23.3 \\
\hline North West & 38.1 & 34.8 & 33.4 & 33.9 & 31.7 \\
\hline Yorkshire and the Humber & 38.7 & 33.6 & 28.5 & 30.4 & 28.7 \\
\hline East Midlands & 30.8 & 29.8 & 27.5 & 25.1 & 24.7 \\
\hline West Midlands & 28.9 & 26.0 & 23.4 & 25.7 & 22.7 \\
\hline East of England & 24.8 & 23.0 & 20.2 & 18.0 & 19.0 \\
\hline London & 32.7 & 32.9 & 27.2 & 25.7 & 27.0 \\
\hline South East & 26.2 & 21.2 & 20.0 & 16.4 & 17.6 \\
\hline South West & 30.6 & 26.1 & 21.5 & 20.2 & 20.4 \\
\hline England & 30.9 & 27.9 & 24.7 & 23.3 & 23.4 \\
\hline
\end{tabular}

Table 2 Mean number of teeth with experience of dental decay in five-year-olds with decay experience in England by region (2008, 2012, 2015, 2017 and 2019), reproduced with permission from Public Health England under the terms of the Open Government Licence ${ }^{19}$

\begin{tabular}{|c|c|c|c|c|c|}
\hline \multirow{2}{*}{ Region name } & \multicolumn{5}{|c|}{$\begin{array}{l}\text { Mean number of teeth with experience of dental decay in } \\
\text { five-year-olds with decay experience ( } n \text { ) }\end{array}$} \\
\hline & 2008 & 2012 & 2015 & 2017 & 2019 \\
\hline North East & 3.5 & 3.4 & 3.4 & 3.1 & 3.5 \\
\hline North West & 3.8 & 3.7 & 3.8 & 3.7 & 3.8 \\
\hline Yorkshire and the Humber & 3.7 & 3.6 & 3.6 & 3.7 & 3.8 \\
\hline East Midlands & 3.2 & 3.1 & 3.3 & 3.3 & 3.4 \\
\hline West Midlands & 3.2 & 3.2 & 3.1 & 3.2 & 3.2 \\
\hline East of England & 3.2 & 3.3 & 3.2 & 3.3 & 3.3 \\
\hline London & 3.9 & 3.7 & 3.7 & 3.7 & 3.4 \\
\hline South East & 3.3 & 3.2 & 3.2 & 3.2 & 3.3 \\
\hline South West & 3.3 & 3.0 & 3.1 & 3.1 & 3.2 \\
\hline England & 3.4 & 3.4 & 3.4 & 3.4 & 3.4 \\
\hline
\end{tabular}

of DGAs within the NHS or private practice effectively ceased, requiring all patients needing such treatment to be referred to a suitable hospital.

The extraction of carious teeth has become the most common reason for hospital admission of under-18-year-olds in England, with a total of 59,314 tooth extractions in 2017-2018, of which 38,385 extractions were because of caries. ${ }^{16}$ This situation has raised questions from professional healthcare bodies and the media over the perceived failure to control a largely preventable disease. ${ }^{17,18}$ The aim of this paper is to review the demographic factors related to hospital admissions for dental extractions, identifying those localities with the greatest proportion of admissions, and to consider how the present situation can be addressed effectively. The focus of this review is mainly on five-year-old children, since by that age the aetiological factors for dental caries and treatment needs will have become established. The review is also limited to England, which has the largest available source of data.

\section{Dental caries prevalence in England}

The National Dental Epidemiology Programme for England (Public Health England) surveys for five-year olds have shown that there is wide variation in the prevalence and also severity of dental caries. This variation is largely characterised by geographical area, level of deprivation and ethnic group. ${ }^{19}$ In the 2019 survey (data collected in 2018) of five-year olds, $34.3 \%$ of children living in the more deprived areas had caries experience compared to $13.7 \%$ of children from less deprived areas. While five-year-old children in the North West of England have the highest caries prevalence at $31.7 \%$, there has been a sharp decline in prevalence in the region since 2008. All regions showed a decline in prevalence between 2008 and 2017; however, the 2019 survey results showed an increase in prevalence in the East of England, London, south east and south west regions (Table 1).

As the majority of children surveyed had no experience of caries, it is the severity of disease in children who have experienced caries that is relevant to this review. Of these children, the mean number of teeth with caries experience in England was constant at 3.4 between 2008 and 2019, with children in the three northern regions showing the highest mean number of carious teeth (Table 2). Within regions, there was variation in the 


\begin{tabular}{|c|c|c|c|c|}
\hline Ethnic group & $\begin{array}{l}\text { Number of children } \\
\text { examined (n) }\end{array}$ & $\begin{array}{l}\text { Prevalence of experience of } \\
\text { dental decay (\%) }\end{array}$ & $\begin{array}{l}\text { Mean number of teeth with } \\
\text { experience of dental decay } \\
\text { among children with any } \\
\text { experience of dental decay } \\
\text { (n) }(95 \% \mathrm{Cl})\end{array}$ & $\begin{array}{l}\text { Prevalence of dental decay } \\
\text { affecting incisors (\%) }\end{array}$ \\
\hline White & 56,817 & 20.6 & 3.2 & 3.6 \\
\hline Mixed & 3,739 & 24.1 & 3.3 & 5.7 \\
\hline Asian/Asian British & 8,166 & 36.9 & 4.0 & 13.2 \\
\hline Black/Black British & 2,953 & 23.2 & 3.3 & 6.1 \\
\hline Other ethnic group & 1,333 & 44.3 & 4.4 & 15.7 \\
\hline Not provided & 5,759 & 19.9 & 3.2 & 4.3 \\
\hline Total & 78,767 & 23.4 & 3.4 & 5.2 \\
\hline
\end{tabular}

prevalence of caries experience in five-yearolds by lower-tier local authority area (LTA; the smallest administrative area). The greatest variation was found in the south east region, where prevalence ranged from $1.1 \%$ to $37.9 \%$.

\section{Caries prevalence and ethnicity}

In England, there is a striking variation of caries prevalence in five-year-olds of different ethnicities. Analysis by ethnic group shows a significantly higher caries prevalence in the 'other ethnic group' (44.3\%) and 'Asian/ Asian British' ethnic groups (36.9\%) than that found in other ethnic groups and other minority ethnic children and compared to those classified as 'white. ${ }^{19}$ The difference is particularly striking for caries affecting the incisor teeth, with almost a fivefold higher prevalence (Table 3 ). This is reflected in the prevalence of caries of the incisor teeth at LTA level, ranging from $0.0 \%$ in six local authorities in England to $15.6 \%$ in Brent, an ethnically diverse area of Inner London. Caries in the deciduous incisor teeth is almost always associated with infant feeding practices, usually influenced by cultural norms. Within ethnic groups, the largest variation in prevalence of caries experience was seen in the white ethnic group, ranging from $14.0 \%$ in the Irish ethnic group to $59.6 \%$ in the Irish Traveller ethnic group. ${ }^{19}$

\section{Caries experience and deprivation}

It is well recognised that social deprivation is an important factor in the prevalence of many non-communicable diseases. In England, the Index of Multiple Deprivation data for 2019 (IMD2019) shows that the pattern of deprivation is complex. The most and least deprived neighbourhoods are spread throughout the country, with pockets of deprivation often surrounded by less deprived areas in every English region. The most deprived neighbourhood in England, according to the IMD2019, is to the east of the Jaywick area of Clacton-on-Sea, Essex. Neighbourhoods in Blackpool, a popular North West holiday destination in the summer months, account for eight of the ten most deprived neighbourhoods nationally, with Anfield in the centre of Liverpool making up the tenth. For income deprivation among children, Middlesbrough and Blackpool are the most deprived in the country. Of the 20 most deprived local authority districts in England, all but Birmingham, Clacton-onSea and Hastings are in the North East or North West regions of the country. Since the 2015 deprivation survey, five neighbourhoods in London, Tower Hamlets, Westminster, Islington, Haringey, Waltham Forest and Lambeth have shown the greatest decrease in deprivation, while Oldham, Rossendale, Walsall, Mansfield and Blackburn with Darwen have shown the greatest increase. However, there has been no change in rank among the five most deprived local authority districts, which now show persistent deprivation.

For the caries experience of five-year-olds in England in 2019, IMD data clearly show a social gradient. The prevalence was $13.7 \%$ in five-year-olds living in the least deprived areas compared with $34.3 \%$ in those living in the most deprived areas. ${ }^{19}$ For children with some evidence of caries experience, the number of carious teeth per child showed a similar variation.

\section{Untreated caries in five-year-olds}

The major component of the decayed, missing and filled teeth (dmft) index is untreated decay into dentine (d3t). On average in 2019, fiveyear-olds with caries experience had 2.7 teeth with untreated cavities. ${ }^{19}$ At a regional level, the mean number ranged from 2.5 teeth in the south west to 3.0 in the North West. There was wider variation at the LTA level, ranging from 1.1 untreated teeth with dentinal caries in Havant, Hampshire to 4.6 teeth in Norwich, Norfolk.

The Care Index is the proportion of carious teeth that received some form of restorative treatment. It gives an indication of the restorative activity of dentists in each area. In 2019, the proportion of carious teeth with evidence of restorative treatment was $10.3 \%$ across England as a whole. This varied between regions, from $6.6 \%$ in the North West to $13.8 \%$ in the south east, and within regions; for example, in the south west, from $1.5 \%$ treated teeth in Torbay to $34.9 \%$ in Stroud. Childhood asthma is increasing in prevalence and is linked to molar and incisor hypoplasia, with increased caries susceptibility. This condition is difficult to treat and often leads to the need for GA extractions.

\section{Hospital GA extraction cases for children (2011-2019)}

Data on NHS DGAs in England are provided by NHS Digital as Outcomes Framework Indicators. ${ }^{20}$ The data are given as finished consultant episodes (FCEs) for children and adolescents aged 0-19 years of age by English region, upper-tier local authority (UTA; a larger administrative area) and LTA (the 
Table 4 Hospital admissions for extraction of one or more teeth (FCEs) $41,42,43$

\begin{tabular}{|c|c|c|c|c|}
\hline \multirow[t]{2}{*}{ Lower tier area } & $\begin{array}{l}\text { FCEs as } \% \text { of } \\
0-19 \text {-year-old } \\
\text { population }\end{array}$ & $\begin{array}{l}\text { FCEs as } \% \text { of } \\
0-5 \text {-year-olds }\end{array}$ & $\begin{array}{l}\text { FCEs as \% of } \\
6-10 \text {-year-olds }\end{array}$ & $\begin{array}{l}\text { FCEs of } \\
0-10 \text {-year- } \\
\text { olds } / 100,000\end{array}$ \\
\hline & 1 & 1 & 1 & 2 \\
\hline Blackpool* & 1 & 1.2 & 2 & 1,557 \\
\hline Hyndburn* & 1 & 1.2 & 2 & 1,547 \\
\hline Rotherham** & 1 & 1.1 & 2.1 & 1,616 \\
\hline Sheffield** & 1 & 1 & 2 & 1,480 \\
\hline Torbay & 1 & 0.9 & 1.9 & 1,355 \\
\hline Barnsley** & 0.9 & 0.8 & 1.8 & 1,271 \\
\hline Northumberland $t$ & 0.9 & 1 & 1.6 & 1,332 \\
\hline Wigan* & 0.9 & 0.7 & 1.8 & 1,214 \\
\hline North East Lincolnshire & 0.9 & 0.9 & 2.1 & 1,438 \\
\hline Blackburn with Darwen* & 0.8 & 1 & 1.6 & 1,267 \\
\hline Wakefield** & 0.8 & 0.7 & 1.7 & 1,149 \\
\hline Preston* & 0.8 & 0.9 & 1.6 & 1,224 \\
\hline Bristol & 0.7 & 0.7 & 1.4 & 1,010 \\
\hline Liverpool* & 0.7 & 0.7 & 1.5 & 1,041 \\
\hline Burnley* & 0.7 & 0.6 & 1.5 & 1,047 \\
\hline West Lancashire* & 0.7 & 0.8 & 1.7 & 1,221 \\
\hline North Devon & 0.7 & 0.6 & 1.4 & 977 \\
\hline Telford \& Wrekin & 0.7 & 0.9 & 1.3 & 1,080 \\
\hline
\end{tabular}
Key:
FCE = finished consultant episodes (hospital admissions for extraction of one or more teeth). Those for $0-5$-year-olds likely to be for extraction of primary teeth only. Those for 6-10-year-olds will include extraction of both primary and permanent teeth ${ }_{* *}^{*}=$ North West region $* *=$ Yorkshire region $\dagger=$ North East region

smallest administration area). The FCEs are for extractions where the primary diagnosis is caries, and although not specified, for the 0 -5-year-olds, the extracted teeth will be primary teeth and for the 6-10-year-olds will include both primary and permanent teeth (Table 4). The numbers of extractions may be greater than recorded, as they do not include cases not led by a dental consultant. Many cases do not have a treatment planning input from a paedodontic specialist, sometimes leading to the need for unnecessary repeated hospital admission, which may not be included in the data. ${ }^{21,22,23}$ The data do not distinguish the type of anaesthesia; however, the majority of FCEs, especially for the younger age groups, will have been under GA. In the London region, which has the highest number of children with FCEs for dental extraction due to caries, the number of cases has fallen since 2014. However, in the North West and Yorkshire and Humber regions, with the second and third highest numbers, there has been little change during this period. The LTA data for 2018/19 show that in the North West region, there is a cluster of towns in close geographical proximity with a high percentage of FCEs in the $0-10$ age group. ${ }^{20}$ To a lesser extent, this is also true of several towns and cities in the Yorkshire region. Most of these LTAs are characterised by both deprivation and a higher than average proportion of minority ethnicities.

Of the 18 LTAs in England with the highest percentage of FCEs of 0.7 or more for the 0-19 age group, eight are in the North West region and four are in Yorkshire. In both Blackpool and Hyndburn, during the 12 months of 2018/19, more than 1 in 100 children aged five years or younger had a hospital dental extraction, as did 2 in 100 children in the 6-10-year-old age group. In South Yorkshire, data for Rotherham and Sheffield show similar proportions. Hyndburn
LTA is based on the town of Accrington and is bounded by Blackburn and Darwen to the west and Burnley to the east, with Bolton, Bury, Rochdale and Wigan to the south. These LTAs make it a roughly semi-circular area, approximately 25 miles wide by 16 miles north to south, lying to the north of the Manchester conurbation. Rotherham and Sheffield are adjacent in South Yorkshire.

\section{Discussion}

In his presentation to the 1984 Scientific Meeting of the International Epidemiological Association in Vancouver, the late Geoffrey Rose compared the two approaches to disease control - the population-wide approach and the high-risk approach, which seeks to identify those individuals within a population who are at higher risk and for whom individualbased interventions can be offered. ${ }^{24}$ The major advances in disease control in the last 100 years have been achieved by a governmentled population-wide approach, examples being immunisation against childhood diseases, tuberculosis and polio, and the Clean Air Act of 1952 in the UK. Such strategies reach and benefit almost the whole population, irrespective of socioeconomic status or ethnicity, and require little or no personal involvement or compliance. They are also cost-effective in reducing both the social and financial impact on public services. In contrast, strategies to reduce the prevalence of dental caries using individual-based interventions have not always been successful in areas and communities showing the highest caries prevalence. However, in Scotland, with a historically high prevalence of childhood caries, the Childsmile programme has been a striking success, especially in areas of deprivation, achieving the target for $60 \%$ of primary schoolchildren being caries-free. ${ }^{25}$

In England, although the prevalence of childhood caries has fallen in much of the country, it has remained stubbornly high in much of the North West and in some areas appears to be increasing, and this is reflected in the hospital admissions data. Although clear and prescriptive guidance was issued to primary care dental teams in the form of the NHS document Delivering better oral health: an evidence-based toolkit for prevention, ${ }^{26}$ this innovation appears to have had little impact in high-prevalence areas. However, it must be stated that this guidance is not supported by additional NHS funding, and neither has 
the implementation of some excellent local preventive programmes such as Smile4Life in the North West region. ${ }^{27} \mathrm{~A}$ free fluoride toothpaste distribution scheme in North West England produced a $16 \%$ reduction in caries experience with a 1,450 ppm sodium fluoride/ monofluorophosphate paste. ${ }^{28}$ However, the absolute caries reduction was not related to deprivation status and the programme did not reduce deprivation-related health inequalities. ${ }^{29}$ The investigators concluded that targeting was unlikely to improve the effectiveness of the programme.

By the middle of the last century, the evidence for the aetiology of caries had become clear. A frequent dietary intake of simple sugars, especially sucrose and other monosaccharides and disaccharides, initiates the carious process and drives lesion progression..$^{30}$ Early childhood caries is usually related to poor infant feeding, especially sugar-sweetened drinks in feeding bottles, often leading to the need for a DGA. Dietary analysis and counselling can be effective at an individual level but requires motivation and long-term behaviour change. The simplest dietary advice can be the most effective. ${ }^{31}$

While the intake of simple sugars drives the carious process, the topical and systemic application of fluoride can attenuate the process. Water fluoridation is the only oral health improvement intervention that does not require behaviour change by individuals. The first substantive community water fluoridation scheme in England was introduced in Birmingham in 1964. The success of this scheme is clear from many studies. However, in the context of this review, most relevant is the reported FCEs of $0.1 \%$ for the $0-19$ age group in 2018/19, despite including areas of deprivation and a higher than average proportion of minority ethnicities. This compares to that of Manchester of $0.6 \%$ and the average for England of $0.3 \%{ }^{20}$ The Water fluoridation: health monitoring report for England 2018 found that water fluoridation reduced the risk of caries-related hospital dental extractions in the $0-19$ age group and the effect was significantly greater in the most deprived areas. ${ }^{32}$ Indeed, hospital extraction rates have been proposed as an alternative marker for the effectiveness of water fluoridation. ${ }^{33}$ The benefit of water fluoridation on health inequalities is not only seen in the most deprived children but also those of Asian and British/Asian heritage. ${ }^{34}$ Further evidence is provided by an extensive review of variations in the use of general dental anaesthesia for children. ${ }^{35}$ A survey of 1,783 children compared artificially fluoridated water in Newcastle to Manchester. While the level of deprivation for both cities was comparable, there was significantly less caries experience in Newcastle. Interestingly, no significant difference was found when comparing the least deprived quintiles. ${ }^{36}$ Some local schemes have followed Birmingham and some local authorities in northern England are currently considering new schemes. About six million people in England now have a fluoridated water supply and a third of a million have a water supply where the naturally occurring level of fluoride is around the optimal level. Worldwide, over 370 million people are served by water fluoridation schemes. Between 2006 and 2009, local health authorities in the North West and Yorkshire considered the practicalities for the implementation of localised fluoridation schemes. However, because of a judicial review of a proposal for the Southampton area, the northern proposals were not progressed.

In 2012, the UK Health and Social Care Act devolved the statutory responsibility for water fluoridation schemes in England from central government to unitary and UTAs. This legislation included the requirement for formal public consultation on a fluoridation proposal and for collaboration with other local authorities whose populations may be affected by the proposal. ${ }^{37}$ For those not considering water fluoridation, the most common reason was that it would be too difficult to implement within their local authority boundaries due to the complexity of water supplies and would require an agreement with multiple adjacent local authorities. The return of investment of $£ 1$ on targeted supervised tooth-brushing programmes has been estimated as $\mathfrak{£} 3.06$ after five years and $£ 3.66$ after ten years. ${ }^{38}$ For a targeted fluoride varnish programme, the return would be $£ 2.29$ and $£ 2.74$, respectively. On the same basis, water fluoridation would provide a return of investment of $£ 12.71$ and $£ 21.96$.

The United States Centres for Disease Control and Prevention have ranked water fluoridation as one of the ten most important public health measures of all time. In their comprehensive review of the oral health of children in England, Godson, Csikar and White list the nine things that dental professions and paediatricians can do at population level to reduce the prevalence of childhood caries. ${ }^{39}$ Of these nine, only water fluoridation can reach the whole community, irrespective of deprivation and ethnicity. The Royal College of Paediatrics and Child Health have recommended that the UK government should provide resource and support for local authorities to implement water fluoridation, particularly for areas where there is a high prevalence of caries. ${ }^{40}$

\section{Conclusion}

Despite an overall improvement in recent years, the available evidence indicates that oral health improvement programmes implemented at primary care level have not improved the oral health of children in a number of clearly defined local areas, mostly in northern England. Young children in these areas are now three times more likely than children in other parts of the country to be referred to hospital for a DGA. Action at regional and national levels of government is now needed. NHS hospitals have come under unprecedented pressure for acute admissions because of COVID-19. Combined with the increasing burden on healthcare resources from rising levels of obesity and type 2 diabetes, both related to dietary factors, the added burden of largely preventable DGAs calls for a radical approach to prevention.

The case for targeted water fluoridation schemes in localised northern areas is now so strong that the barriers to implementation must be overcome and compromises accepted where necessary. The safety, efficacy and methodology to implement water fluoridation in England have been established; ${ }^{37}$ only lacking is the resolution to do so. Failure to act now will perpetuate the relevance of the biblical quotation.

\section{Conflict of interest}

The author declares no conflict of interest.

\section{References}

1. Hancocks S. Suffer the little children. Br Dent J 2011; 210: 341.

2. Moles D, Ashley P. Hospital admissions for dental care in children: England 1997-2006. Br Dent J 2009; 206: E14.

3. Olley R C, Hosey M T, Renton T, Gallagher J. Why are children still having preventable extractions under general anaesthetic? A service evaluation of the views of parents of a high caries risk group of children. Br Dent J 2011; 210: E13.

4. Ramdaw A, Hosey M T, Bernabé E. Factors associated with use of general anaesthesia for dental procedures among British children. Br Dent J 2017; 223: 339-345.

5. Anderson W, Ahmed H. A retrospective analysis of hospitalisation for diseases of the pulp and periapical tissues in NHS Grampian 2011-2015: geographic, socioeconomic and increased primary care availability effects. Br Dent J 2019; 226: 951-954.

6. Harper R, Nevill A, Senghore N et al. Socioeconomic and ethnic status of two-and three-year-olds undergoing dental extractions under general anaesthesia in Wolverhampton, 2011-2016. Br Dent J 2019; 226: 349-353. 
7. Mortimore A, Wilkinson R, John J H. Exploring the potential value of using data on dental extractions under general anaesthesia (DGA) to monitor the impact of dental decay in children. Br Dent J 2017; 222: 778-781.

8. Hood C A, Hunter M L, Kingdon A. Demographic characteristics, oral health knowledge and practices of mothers of children aged 5 years and under referred for extraction of teeth under general anaesthesia. Int J Paediatr Dent 1998: 8: 131-136.

9. Karki A J, Thomas D R, Chestnutt I G. Why has oral health promotion and prevention failed children requiring general anaesthesia for dental extractions? Community Dent Health 2011; 28: 255-258.

10. Bridgman C M, Ashby D, Holloway P J. An investigation of the effects on children of tooth extraction under general anaesthesia in general dental practice. Br Dent J 1999; 186: 245-247.

11. Goodwin M, Sanders C, Davis G, Walsh T, Pretty I A. Issues Arising Following a Referral and Subsequent Wait for Extraction Under General Anaesthetic: Impact on Children. BMC Oral Health 2015; 15: 3.

12. Poswillo D. General Anaesthesia, sedation and resuscitation in dentistry: Report of an Expert Working Party for the Standing Dental Advisory Committee. London: Department of Health, 1990.

13. Mokhtar S. Child Mortality Rates Associated with General Anaesthesia for Dentistry in England and Wales. London: University of London, 2003. MSc Thesis.

14. General Dental Council. Maintaining Standards: Guidance to Dentists on Professional and Personal Conduct. London: General Dental Council, 1998.

15. Department of Health. A conscious decision: a review of the use of general anaesthesia and conscious sedation in primary dental care. London: Department of Health, 2000.

16. Anonymous. Almost all child hospital tooth extractions caused by decay. Br Dent J 2019; 226: 392.

17. Therrien A. More children having teeth out in hospital in England. BBC News (London) 2018 January 13.

18. Donnelly L. 105 children a day having rotten teeth taken out in hospital. The Telegraph (London) 2019 March 6.

19. Public Health England. National Dental Epidemiology Programme for England: Oral health survey of 5-yearolds 2019 - A report on the variations in prevalence and severity of dental decay. 2020. Available at https:// assets.publishing.service.gov.uk/government/uploads/ system/uploads/attachment_data/file/873492/ NDEP_for_England_OH_Survey_5yr_2019_v1.0.pdf (accessed July 2020).

20. Public Health England. Hospital tooth extractions of 0 to 19 year olds. 2019. Available online at https:// www.gov.uk/government/publications/hospitaltooth-extractions-of-0-to-19-year-olds (accessed July 2020).

21. Harrison M, Nutting L. Repeat general anaesthesia for paediatric dentistry. Br Dent J 2000; 189: 37-39.

22. Kakaounaki E, Tahmassebi J F, Fayle S A. Further dental treatment needs of children receiving exodontia under general anaesthesia at a teaching hospital in the UK. Int J Paediatr Dent 2006; 16: 63-69.

23. Kruger E, Tennant M. Potentially preventable hospital separations related to oral health: a 10 -year analysis. Aust Dent J 2015; 60: 205-211.

24. Rose G. Sick Individuals and Sick Populations. Int J Epidemiol 1985; 14: 32-38.

25. NHS Scotland. Childsmile. Available online at http:// www.child-smile.org.uk/index.aspx (accessed August 2020).

26. Public Health England. Delivering better oral health: an evidence-based toolkit for prevention - Third edition. Available at https://assets.publishing.service.gov.uk/ government/uploads/system/uploads/attachment_ data/file/605266/Delivering_better_oral_health.pdf (accessed July 2020).

27. NHS. SMILE4LIFE - Starting Well. 2017. Available online at https://www.england.nhs.uk/primary-care/ dentistry/smile4life/ (accessed August 2020).

28. Davis $\mathrm{G} \mathrm{M}$, Worthington H V, Ellwood R P etal. A randomised controlled trial of the effectiveness of providing free fluoride toothpaste from the age of 12 months on reducing caries in 5-6 year old children. Community Dent Health 2002; 19: 131-136.

29. Ellwood R P, Davis G M, Worthington $\mathrm{H}$ V et al. Relationship between area deprivation and the anticaries benefit of an oral health programme providing free fluoride toothpaste to young children. Community Dent Oral Epidemiol 2004; 32: 159-165.

30. Levine R S, Stillman-Lowe C R. The Scientific Basis of Oral Health Education. 8th (international) ed. Switzerland: Springer Nature AG, 2019.

31. Levine R S. Might one simple question indicate a child's caries risk and guide preventive advice? Br Dent J 2019; 227: 834-836.

32. Public Health England. Water Fluoridation: Health monitoring report for England 2018. 2018. Available online at https://www.gov.uk/government/ publications/water-fluoridation-health-monitoringreport-for-england-2018 (accessed August 2020)

33. Elmer T B, Langford J W, Morris A J. An alternative marker for the effectiveness of water fluoridation: hospital extraction rates for dental decay, a two-region study. Br Dent J 2014; 216: E10.
34. Weston-Price S, Copley V, Smith H, Davies G M. A multivariable analysis of four factors affecting caries among five-year-old children; deprivation, ethnicity, exposure to fluoridated water and geographic region. Community Dent Health 2018; 35: 217-222.

35. Broomhead T, Rodd H D, Baker S R et al. A rapid review of variation in the use of dental general anaesthetics in children. Br Dent J 2020; 229: 31-39.

36. McGrady M G, Ellwood R P, Maguire A et al. The association between social deprivation and the prevalence and severity of dental caries and fluorosis in populations with and without water fluoridation. BMC Public Health 2012; 12: 1122

37. Public Health England. Improving oral health: a community water fluoridation toolkit for local authorities. 2016. Available online at https://www.gov.uk/government/ publications/improving-oral-health-community-waterfluoridation-toolkit (accessed July 2020).

38. Public Health England. Return on investment of oral health improvement programmes for $0-5$ year olds. 2016. Available at https://assets.publishing.service.gov. uk/government/uploads/system/uploads/attachment data/file/560973/ROI_oral_health_interventions.pdf (accessed July 2020)

39. Godson J, Csikar J, White S. Oral health of children in England. Arch Dis Child 2018; 103: 5-10

40. RCPCH. State of Child Health. 2020. Available online at https://stateofchildhealth.rcpch.ac.uk/evidence/ prevention-of-ill-health/oral-health/ (accessed July 2020).

41. Office for National Statistics. Dataset: Estimates of the population for the UK, England and Wales, Scotland and Northern Ireland. 2020. Available online at https:// www.ons.gov.uk/peoplepopulationandcommunity/ populationandmigration/populationestimates/ datasets/populationestimatesforukenglandand walesscotlandandnorthernireland (accessed July 2020).

42. NHS Digital. NHS Outcomes Framework Indicators - February 2020 Release. 2020. Available online at https://digital.nhs.uk/data-and-information/ publications/statistical/nhs-outcomes-framework/ february-2020 (accessed July 2020)

43. NHS Digital. 3.7.ii Tooth extractions due to decay for children admitted as inpatients to hospital, aged 10 years and under. 2020. Available online at https:// digital.nhs.uk/data-and-information/publications/ statistical/nhs-outcomes-framework/february-2020/ domain-3-helping-people-to-recover-from-episodes of-ill-health-or-following-injury-nof/3-7-ii-toothextractions-due-to-decay-for-children-admitted-asinpatients-to-hospital-aged-10-years-and-under (accessed July 2020) 